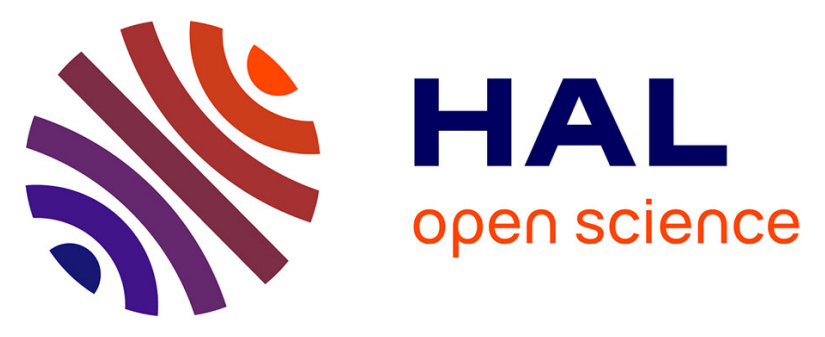

\title{
Study of bioactive glass ceramic for use as bone biomaterial in vivo: investigation by Nuclear Magnetic Resonance and Histology
}

Siwar Mosbahi, Hassane Oudadesse, Eric Wers, Moez Trigui, Bertrand

Lefeuvre, Claire Roiland, Hafed Elfeki, Abdelfatteh Elfeki, Tareq Rebai, Hassib Keskes

\section{To cite this version:}

Siwar Mosbahi, Hassane Oudadesse, Eric Wers, Moez Trigui, Bertrand Lefeuvre, et al.. Study of bioactive glass ceramic for use as bone biomaterial in vivo: investigation by Nuclear Magnetic Resonance and Histology. Ceramics International, 2016, 42 (4), pp.4827-4836. 10.1016/j.ceramint.2015.11.168 . hal-01240651

\section{HAL Id: hal-01240651}

\section{https://hal-univ-rennes1.archives-ouvertes.fr/hal-01240651}

Submitted on 18 Dec 2015

HAL is a multi-disciplinary open access archive for the deposit and dissemination of scientific research documents, whether they are published or not. The documents may come from teaching and research institutions in France or abroad, or from public or private research centers.
L'archive ouverte pluridisciplinaire HAL, est destinée au dépôt et à la diffusion de documents scientifiques de niveau recherche, publiés ou non, émanant des établissements d'enseignement et de recherche français ou étrangers, des laboratoires publics ou privés. 
Study of bioactive glass ceramic for use as bone biomaterial in vivo: investigation by Nuclear Magnetic Resonance and Histology.

Siwar Mosbahi ${ }^{1,2}$, Hassane Oudadesse ${ }^{1}$, Eric Wers ${ }^{1}$, Moez Trigui ${ }^{2}$, Bertrand Lefeuvre ${ }^{1}$, Claire Roiland ${ }^{1}$, Hafed Elfeki ${ }^{3}$, Abdelfatteh Elfeki ${ }^{4}$, Tareq Rebai ${ }^{2}$ and Hassib Keskes ${ }^{2}$.

${ }^{1}$ University of Rennes 1, UMR CNRS 6226, Campus de Beaulieu, 35042 Rennes, France

${ }^{2}$ Orthopaedic and Traumatology Laboratory Sfax Faculty of Medicine Sfax, Tunisia

${ }^{3}$ Science Materials and Environement Laboratory, Sfax Faculty of Science, Sfax, Tunisia

${ }^{4}$ Animal Ecophysiology Laboratory, Sfax Faculty of Science, Department of Life Sciences, Sfax, Tunisia

Corresponding author: hassane.oudadesse@univ-rennes1.fr 
Abstract:

The performance of the porous glass ceramic doped with $10 \%$ wt Zinc and 2\% wt TiN (46S6-10Zn), in the restoration of critical diaphyseal bone defect, was evaluated by several physicochemical methods and histological studies. The critical defect in rabbits was created and then filled with 46S6-10Zn. At different periods after implementation, animals were sacrificed. Samples were harvested for exploration. The nuclear magnetic resonance (MAS-NMR) of ${ }^{31} \mathrm{P}$ and ${ }^{29} \mathrm{Si}$ illustrates the progressive degradation of 46S6$10 \mathrm{Zn}$ in favor to of the formation and the development of biological apatite. Therefore, after one month of implementation, MAS- NMR ${ }^{29}$ Si proves the presence of $\mathrm{Q}^{2}(25 \%)$, $Q^{3}(73 \%)$ and $Q^{4}(2 \%)$. However, after six months, the disappearance of all these species was revealed and characterized by the 46S6-10Zn dissolution. Besides, MASNMR ${ }^{31} \mathrm{P}$ demonstrates the presence of $\mathrm{Q}_{\mathrm{c}}{ }^{0}(4 \%), \mathrm{Q}_{\mathrm{HA}}{ }^{0}(55 \%)$ and $\mathrm{Q}_{\mathrm{a}}{ }^{0}(41 \%)$ after one month. Nevertheless, six months later, we observe the presence of $\mathrm{Q}_{\mathrm{HA}}{ }^{0}(80 \%)$ and $\mathrm{Q}_{\mathrm{a}}{ }^{0}$ (20\%). Histological study demonstrates an intimate contact of 46S6-10Zn surrounding bone after one month of implantation. However, after four months, mature bone matrix became calcified and the implanted 46S6-10Zn began to be degraded. Moreover, nine months later, 46S6-10Zn was nearly resorbed and replaced by a calcified tissue in the periphery and an osteoid tissue in the middle of bone defects.

Key words: Porous glass ceramic ; Nuclear magnetic resonance; Crystalline structure; Cells attachment. 


\section{Introduction:}

Bone defects caused by various reasons such as trauma, infection, tumor, congenital deformity, etc., still a clinically unsolved puzzle. The autogenous bone transplantation is the optimum choice today, but it cannot satisfy the clinical demand because of its limited source and even worse, it may causes damage to the donor site of transplantation or even complications, sometimes [1]. This problem leads experts to discover synthetic materials that have a potential restorative effect of bone defects. In this study we are interested in bioactive glasses (46S6) as support doped with Zinc (Zn) and titanium (Ti).

Bioactive glasses are widely used in the clinical repair of bone defects, because they are spontaneously bonded and integrated with the bone in the living body through the rapid formation of a thin hydroxycarbonate-apatite layer on the material surface when implanted or in contact with biological fluids [2]. Bioactive glasses are a subset of inorganic bioactive materials as well, which are capable of reacting with physiological fluids to form tenacious bonds to the bone through the formation of bone-like hydroxyapatite layers and the biological interaction of collagen with the material surface [3]. It has been found that reactions on bioactive glass surfaces lead to the release of critical concentrations of soluble Silicon $(\mathrm{Si})$, Calcium $(\mathrm{Ca})$, Phosphorus $(\mathrm{P})$ and Sodium $(\mathrm{Na})$ ions, which induce favorable intracellular and extracellular responses, leading to the rapid bone formation [4]. Bioactive glass is an amorphous system which promotes its association with other elements such as strontium [5], magnesium [6] and zinc [7] and other molecules such as bisphonates [8]. Zinc is an essential trace element for the boby. It assures several functions: metabolism of cells [9], wound healing [10] 
and it stimulates cell proliferation and differentiation, protein synthesis in osteoblastic cells $[10,11]$ as well. In a previous study, it was demonstrated that, after immersion of $46 \mathrm{~S} 6$ and $46 \mathrm{~S} 6-10 \mathrm{Zn}$ in the SBF, the incorporation of $\mathrm{Zn}$ in the vitreous matrix based on 46S6 increases the bioactivity of this biomaterial [7]. This highlights the role of zinc in the development, differentiation and proliferation of osteoblasts. Its deficiency decreases bone weight and delays growth in bone metabolism. Zinc deficiency results in a retardation of bone growth, development, and maintenance of bone health $[12,13]$. It has a stimulatory effect on bone formation and mineralization in vitro and vivo $[14,15]$. The biocompatibility of $46 \mathrm{~S} 6-10 \mathrm{Zn}$ was maximized by the incorporation of titanium in its matrix. Therefore, it was reported that the excellent biocompatibility of titanium and its alloys with bone tissue can be explained by the unique characteristics of titaniumbone interface [16].

Our study aimed to evaluate the behavior of porous glass ceramic doped with $\mathrm{Zn}$ and $\mathrm{Ti}$ in the restoration of critical diaphyseal bone defect in rabbits after its implementation during one, four, six and nine months.

For the evaluation of our biomaterial's behavior (46S6-10Zn), several physicochemical techniques were used such as X- ray diffraction (DRX), Infra- red analysis (FTIR), Energy-dispersive X-ray (EDS) and solid-state nuclear magnetic resonance (MASNMR). The evolution of initial biomaterial was realized in function of the time implementation. Additionally, the histological study was used to evaluate the osseointegration and the resorption of this composite after one, four and nine months.

2. Materials and Methods: 
2.1 Bioactive glass synthesis

Bioactive glasses were synthesized by freeze-drying method. Their elaboration was carried out using sodium metasilicate $\left(\mathrm{Na}_{2} \mathrm{SiO}_{3}\right)$, silicon dioxide $\left(\mathrm{SiO}_{2}\right)$, calcium metasilicate $\left(\mathrm{CaSiO}_{3}\right)$ and sodium metaphosphate $\left(\mathrm{Na}_{3} \mathrm{P}_{3} \mathrm{O}_{9}\right)$. Powders were weighed and mixed in a polyethylene bottle, for $2 \mathrm{~h}$ using a planetary mixer. $46 \mathrm{~S} 6-10 \mathrm{Zn}$ was synthesized from the composition of $46 \mathrm{~S} 6$ (46 $\operatorname{mass} \% \mathrm{SiO}_{2}$ (silica), 24 mass $\% \mathrm{CaO}$ (calcium oxide or lime), 24 mass $\% \mathrm{Na}_{2} \mathrm{O}$ (Sodium oxide) and 6 mass $\% \mathrm{P}_{2} \mathrm{O}_{5}$ (Phosphorus pentoxide). Moreover, this bioactive glass composition 46S6 was studied by introducing 10 mass $\%$ zinc oxide and 2 mass $\%$ TiN to create porosity [17].

The premixed mixtures were melted at $1250^{\circ} \mathrm{C}$ in platinum crucibles to avoid the risk of contamination. The fusion temperature of platinum is of $1760^{\circ} \mathrm{C}$. The first rise of temperature rate was $10^{\circ} \mathrm{C} \min ^{-1}$ and was held at $900^{\circ} \mathrm{C}$ for $1 \mathrm{~h}$ to achieve the decarbonatation of all products. The samples were cast in preheated brass molds, in order to form cylinders of $13 \mathrm{~mm}$ in diameter, and annealed at $565^{\circ} \mathrm{C}$ for $4 \mathrm{~h}$ near the glass transition temperature. The obtained cylinders were used for the 'in vivo' studies. The prepared bioimplants were sterilized by $\gamma$-irradiation from a ${ }^{60} \mathrm{Co}$ source gamma irradiation at a dose of 25 Gy (Equinox, UK) using standard procedures for medical devices.

\subsection{Animal model}

Twenty five mature New Zealand rabbits, nine months old and weighing $1.6-2 \mathrm{~kg}$, were used. Animals were bred in the Central Animal House and they were randomly distributed into 2 groups: 
*G1 (T) none operated and none implanted,

*G2 (46S6-10Zn) operated and implanted with 46S6-10Zn.

The animals were placed in individual cages, under standard conditions (room temperature $22 \pm 2{ }^{\circ} \mathrm{C}$, relative humidity $55 \pm 5 \%$ and illumination with a $12 \mathrm{~h} / 12 \mathrm{~h}$ of light/darkness photoperiod), fed with a full rabbit's on a pellet diet (Sico, Sfax, Tunisia), libitum added water, and without restriction of movement, according to the animal experimentation EU rules.

\subsection{Animal anesthesia}

Anesthesia was induced with $10 \mathrm{mg} / \mathrm{kg}$ of ketamine (KetaminoL, Intervet International $\mathrm{GmbH}$, Unterschleibheim, Germany) and $0.1 \mathrm{mg} / \mathrm{kg}$ of Xylazine (Rompun, Bayer Healthcare, PuteauxFrance). Supplemented local anesthesia was applied after $15-20$ min using $4 \mathrm{mg} / \mathrm{kg}$ carprofen (Rimadyl, Pfizer, Paris, France) depending on body weight.

\subsection{Surgical operations}

The tibia was implanted and stabilized by mini external fixator. Cutaneous and subcutaneous incisions on the inner face of the tibia followed by an opening of the

muscular aponeurose were carried out. A gap (1 cm in diameter) in the mid-diaphyseal level of the tibia was created aseptically. 46S6-10Zn filled the loss of osseous substance for the second group. Animals were killed after one, four, six and nine months and bones were harvested (Fig. 1). 


\subsection{Physicochemical exploration}

The evaluation of the crystalline and morphological structure of the surface and the kinetic of bioimplant degradation and resorption were carried out by using complementary methods such as XRD, FTIR, EDS and MAS- NMR. X-ray diffraction (XRD) was studied by using a diffractometer (Philips X'Pert-MPD system with a CuKa wave length of $1.5418 \AA$ ). The diffractometer was operated at $40 \mathrm{kV}$ and $30 \mathrm{~mA}$ at a $2 \theta$ range from $10^{\circ}-70^{\circ}$ employing a step size of $0.02^{\circ} / \mathrm{s}$. Samples were dried for $24 \mathrm{~h}$ at 65 ${ }^{\circ} \mathrm{C}$ and weighed accurately. Fourier transformed infrared analysis (FTIR; Nicolet Magna-IR 550 spectrometers, Madison, Wisconsin) was performed to identify the nature of the chemical groups and their evolution versus time of implementation. The samples were small pellets, of $0.5 \mathrm{~cm}$ diameter, obtained by pressing the powder with $\mathrm{KBr}$. Quantification of calcium (Ca, mol \%), phosphorus (P, mol \%) and zinc (Zn, mol $\%)$ in the interface $46 \mathrm{~S} 6-10 \mathrm{Zn}$ - bone was determined by the dispersive X-ray spectroscopic additionally the ratio of calcium to phosphorus $(\mathrm{Ca} / \mathrm{P})$ was calculated at each period. Nuclear Magnetic Resonance (NMR) using a Bruker MAS spectrometer ASX300 (7.05 T) was employed to highlight the new formation of bone and the degradation of biomaterial.

\subsection{Histological studies}

The cells' attachment and bone formation have been studied by using histological study. After one, four and nine months the implanted bone was harvested from each rabbit and 
fixed in Burdack, (formalin). The time delay was selected to assess the performance of the biomaterials on bone formation before degradation. Samples were included in a mixture of polymethylmethacrylate (PMMA) and glycolmthacrylate (GMA) without prior decalcification. Sections 6 to $7 \mu \mathrm{m}$ thick were debited along a transverse plane using a sliding microtome (Reichert-Jung).

\subsection{Statistical analysis}

The statistical analysis of the data was carried out using the Student's t-test. The determinations were performed from 5 animals per group. All values were expressed as means $\pm \mathrm{SE}$ at the significance level $2 \mathrm{a}=0.05$

3. Results

3.1 Crystalline structure by using X-ray diffraction (XRD)

Data reported by XRD show structural changes of the porous glass ceramic before and after implementation. Therefore, before implementation, biomaterial shows the presence of two crystal phases referenced in JCPDS: major crystalline phase $\left(\mathrm{Na}_{4} \mathrm{Ca}_{4} \mathrm{Si}_{6} \mathrm{O}_{18}\right)$ and a secondary crystalline phase $\left(\mathrm{Na}_{2} \mathrm{Ca}_{4}\left(\mathrm{PO}_{4}\right)_{2} \mathrm{SiO}_{4}\right)$ as shown in Fig.

2. After one month of implementation, we observe the persistence of these two phases of the 46S6-10Zn $\left(\mathrm{Na}_{4} \mathrm{Ca}_{4} \mathrm{Si}_{6} \mathrm{O}_{18}\right.$ and $\left.\mathrm{Na}_{2} \mathrm{Ca}_{4}\left(\mathrm{PO}_{4}\right)_{2} \mathrm{SiO}_{4}\right)$. This result exhibits the onset degradation of this composite. Four months later, the diffractogram illustrates the disappearance of the two phases of $46 \mathrm{~S} 6-10 \mathrm{Zn}$ and the appearance of two lines of 
biological apatite which indicate the progressive mineralization and nucleation of bone. Finally, after nine months we observe a diffractogram similar to that of biological bone. All these findings demonstrate the biodegradability of 46S6-10Zn and its progressive replacement by the apatite (Fig. 2).

3.2 Molecular vibrations: Infra- red analysis (FTIR)

Spectrum of 46S6-10Zn before and after its implementation (Fig. 3) illustrates several changings. 46S6-10Zn before implementation, indicates the presence of 4 bands of Si-O-Si at a wave-number $503 \mathrm{~cm}^{-1}$ and $\mathrm{Si}-\mathrm{O}$ at 745, 932 and $1036 \mathrm{~cm}^{-1}$. In addition, we note the presence of three bands of P-O at the wave-numbers 580, 645 and $1048 \mathrm{~cm}^{-1}$. One month later of implementation, we observe the presence of three bands of Si-O respectively at the wave-number of 448,526 and $920 \mathrm{~cm}^{-1}$. Also, we notice the presence of $\mathrm{P}-\mathrm{O}$ bands and with a chemical displacement respectively at the wavelength of 620,566 and $1028 \mathrm{~cm}^{-1}$. Whereas, the absorption bond at $1657 \mathrm{~cm}^{-1}$ is attributed to amide I. Moreover, the band at $154 \mathrm{~cm}^{-1}$ corresponds to the amide II. All these findings suggest the beginning of 46S6-10Zn degradation and its replacement by the newly formed bone cells compared to carbonated hydroxyapatite used as a reference (Fig. 3). After four months, we illustrate the increasing of biomaterial degradation. Therefore, we notice the presence of Si-O bands with a slight intensity. Moreover, we show the increasing of bonds characterizing amide I and II, besides, we observe the appearance of amide III and the bands of carbonate at the wave numbers 1242,872 , 1409 and $1455 \mathrm{~cm}^{-1}$. These findings explain the disappearance of 46S6-10Zn matrix in favor of the overlapping of the apatite bands. These bands were replaced by $601 \mathrm{~cm}^{-}$ ${ }^{1}, 564 \mathrm{~cm}^{-1}$ and $1028 \mathrm{~cm}^{-1}$ (P-O) group arising from that of the apatite- bone. The P-O 
intensity increased with the advance of implementation time, this exhibits the progression of bone growth with implementation time. This is confirmed by the appearance of the $\mathrm{C}-\mathrm{O}$ band characteristic of bone carbonate group. Moreover, after nine months, all Si-O bands disappeared and replaced by P-O bands, amide I, II, III and carbonates. This highlights the increasing of ours biomaterial (46S6-10Zn) biodegradation and the bone mineralization and formation.

\subsection{Evolution of the mineral composition: Energy- dispersive (EDS)}

As shown in Fig. 4, before implementation, 46S6-10Zn shows a phosphocalcic $\mathrm{Ca} / \mathrm{P}$ ratio of 2.67. After implementation, this value decreased. Therefore, after one month, the attenuation of $\mathrm{Ca} / \mathrm{P}$ value to 1.33 can be explained by the exchanges of these two elements $\mathrm{Ca}$ and $\mathrm{P}$ between biomaterial and nearby tissue. This interchange may lead for the mineralization and the crystallization of the new formed bone.

This $\mathrm{Ca} / \mathrm{P}$ value exhibits the absence of calcium phosphate. Four months later, this value increased to 1.66 which explains the mineralization and the formation of the biological apatite in the interface bone / 46S6-10Zn. After nine months, the $\mathrm{Ca} / \mathrm{P}$ ratio is near to 1.88 which highlights the progression of the bone mineralization. Whereas, silicon value shows a modification before and after implementation, in fact before implementation it was near to 47. After one month of implementation, we observe a height concentration of $\mathrm{Si}$ and $\mathrm{Zn}$. This demonstrates the slowly dissolution of the 46S6-10Zn matrix. After four months, we observe a decreasing of $\mathrm{Si}$ and $\mathrm{Zn}$ concentrations. This highlights the progressive degradation of the 46S6-10Zn. Nine months later, we note a total absence of $\mathrm{Si}$ and the reduction of $\mathrm{Zn}$ value. Data reported 
after nine months explains the degradation and the resorption of 46S6-10Zn and its replacement by bone (Fig. 5).

3.4 Structural evolution after in vivo tests: Nuclear Magnetic Resonance analysis (MAS- NMR)

The ${ }^{29} \mathrm{Si}$ MAS-NMR spectrum obtained for the porous glass ceramic and the results of its deconvolution before implementation are presented by Fig. 6 and table 1. It highlights the location of 2 distinct contributions at $-78 \mathrm{ppm}$ and $-89 \mathrm{ppm}$. There are characteristics of the tetrahedral silicon environment $Q^{2}$ and $Q^{3}$ respectively. $Q^{2}$ represents $21 \%$ whereas $\mathrm{Q}^{3}$ shows $79 \% . \mathrm{Q}^{2}$ and $\mathrm{Q}^{3}$ were calculated by the integrate model DM-FIT 32 software. In a previous study, the deconvolution of the ${ }^{29} \mathrm{Si}$ MASNMR spectrum of $46 \mathrm{~S} 6$ showed the presence of $\mathrm{Q}^{2}(80 \%)$ and $\mathrm{Q}^{3}(20 \%)$ respectively at -78 and -87 ppm. Thus, we notice the inversion of proportions of $\mathrm{Q}^{2}$ and $\mathrm{Q}^{3}$ species. This is may be explained by the crystallization induced by the thermal treatment during the synthesis process of glass ceramic . According to the literature, $\mathrm{Ca}^{2+}$ cations are associated with $\mathrm{Q}^{2}$ species while $\mathrm{Na}^{+}$cations are associated with $\mathrm{Q}^{3}$ species. The ${ }^{29} \mathrm{Si}$ MAS-NMR spectrum shows some structural modifications due to the chemical reaction between glass ceramic and the in vivo biological fluid. The spectrum of control bone exhibits no silicon resonance. It confirms the absence of this nucleus within the bone matrix. After one and four months of implementation, we notice the reduction of these $\mathrm{Q}^{2}$ and $\mathrm{Q}^{3}$ species suggesting the progressive degradation of the biomaterial. The decrease of these species is accompanied by the emergence, the development and the increase of new species $\left(\mathrm{Q}^{4}\right)$, implying the perturbation of the vitreous matrix of 46S6- 
10Zn. The $\mathrm{Q}^{4}$ species characterize condensation of the network and the formation of a silicon-rich layer on the surface of the biomaterial. After 6 months, we observe the disappearance of these $\mathrm{Q}^{2}, \mathrm{Q}^{3}$ and $\mathrm{Q}^{4}$ species which explains the total degradation of the biomaterial (Fig. 6). The ${ }^{31} \mathrm{P}$ MAS-NMR spectrum obtained for the glass ceramic and the results of its deconvolution before and after implementation are presented in Fig. 7 and Table 3. It highlights the location of 2 distinct contributions at $3 \mathrm{ppm}$ and $8 \mathrm{ppm}$. Based on the half height widths, which are located at the position of 1 and $15 \mathrm{ppm}$, we attributed the resonance of $3 \mathrm{ppm}$ to a crystalline phase noted $\mathrm{Q}_{\mathrm{C}}^{0}$ and the other of $8 \mathrm{ppm}$ to an amorphous phase named $\mathrm{Q}_{\mathrm{a}}^{0}$. Both populations are present respectively with $52 \%$ and $48 \%$. Thus, we show an equivalent distribution of phosphorus between the amorphous and the crystallized phases. The ${ }^{31} \mathrm{P}$ MAS-NMR spectrum obtained for the bioglass pure and the results of its deconvolution before implementation (Table 3) illustrates a chemical displacement which characterizes phosphorus in an orthophosphate environment $\mathrm{PO}_{4}{ }^{3-}$ which corresponds to the species $\mathrm{Q}^{0}$. The ${ }^{31} \mathrm{P}$ MAS-NMR spectrum of the implanted 46S6-10Zn (Fig. 7 and Table 4) shows some structural modifications. These changes are due to the chemical reaction between glass and the in vivo biological environment. Therefore, bone illustrates the presence of species, with a chemical displacement of $4 \mathrm{ppm}$ and with half height width of $3 \mathrm{ppm}$, illustring thus, the presence of the carbonate hydroxyapatite $\left(\mathrm{Q}^{0}{ }_{\mathrm{HA}}\right)$. After one month, we show a sharp decrease of the $\mathrm{Q}^{0}$, this highlights the release of phosphorus from the crystallized phases of the glass ceramic under the effect of the surrounding environment. After, four months, this species disappeared. The $\mathrm{Q}^{0}$ a species also decreased with the implementation time advance, but its attenuation is weaker than the other of $\mathrm{Q}^{0}$. These two phases: crystallized and amorphous phases participate in the 
formation of an apatite layer on the surface of the porous glass ceramic. But the largest participation is assured by crystallized phase, which accelerates the degradation of biomaterials. Whereas, after one month, $\mathrm{Q}^{0}{ }_{\mathrm{HA}}$ species, characteristic of hydroxyapatite phosphorus, was formed and was located at $4 \mathrm{ppm}$. This population increased and achieved $80 \%$ after six months of implementation. This data highlights the maturation and the mineralization of newly formed bone tissue.

\subsection{Histological studies}

All the rabbits presented satisfactory postoperative results, with no evidence of inflammation or infection at the surgical site. No adverse reaction was observed during the procedure. This explains the non toxicity of this biomaterial. Regardless of the type of specimen, after one month (Fig. 8), new bone was observed at the implant-bone interface, this explains the biocompatibilty of our composite which was accepted by the body and interacts with its biological system. Therefore, this tissue at the interface bone- bioimpalant is the results of the exchange between biological systems and 46S610Zn which lead to the formation in the first time of an osteiod tissue and after one month this tissue is matured and transformed to a trabecular tissue leading to the osseointegration four months later (Fig. 9). New bone was observed growing into the pores and lead to the formation of calcified bone network. Indeed, this network of these cells is formed from mesenchymal cells, which will be transformed into fibroblasts contained in the collagen bundles which are deposited without apparent orientation. Fibroblasts metamorphosed into active osteoblasts, which are elongated along spans of mineralized bone tissue. The ossification is setting up step by step from the periphery to 
the center and therefore centripetally. This result highlights the pores importance in the neovascularization and the integration of newly formed bone cells in the biomaterial. During this staining technique, we have used a colorant which alters the biomaterial leading to the appearance of yellowish ranges within the bone matrix. The new growth bone is most abundant in the peripheral regions of the implanted zone, near to the bone contact zones. The initiation was done in contact with the biomaterial but never afar of old bone. Toward, the center of the implanted zones, the pores are denser and the cellularity and bone quantity is lower. The contact between the new growth bone and the material is intimate without fibrous interface or encapsulating. The bone "flows" are clearly guided by the 46S6-10Zn pores and seem building bridges from the periphery of bone loss (Fig. 9). Nine months later, the rest of the 46S6-10Zn is invaded by connective tissue. Thereby, from the periphery to the center we see the presence of a fibrocartilaginous tissue, then we show the presence of trabecular bone tissue and in the middle we illustrate the presence of a fibrous connective tissue which mingles with the rest of biomaterial (Fig. 10,11). It represents the neosynthesis sign. This result suggests the degradation of biomaterial and its replacement firstly with an osteoid tissue, which developed and transformed in calcified tissue.

\section{Discussion:}

Owing to its bioactivity, the 46S6-10Zn induces the formation of a hydroxyapatite layer at its interface after its immersion in SBF solution [7]. In this study based on in vivo assays, the biocompatibility of this composite is confirmed by its progressive degradation and its replacement by a newly formed hydroxyapatite layer. XRD 
diffractogram of 46S6-10Zn, after its implementation, shows changes with time progression. Therefore, after one month, we observe the presence of peaks characteric of 46S6-10Zn composite. This explains the slow dissolution of the composite 46S610Zn. This result is confirmed by its behavior when it was in contact with biological fluids. Therefore, a smaller dissolution of the ceramic glass matrix (46S6-10Zn) generates a smaller formation of the silica rich layer [7]. Four months later, we saw the disappearance of the peaks of $\mathrm{Na}_{4} \mathrm{Ca}_{4} \mathrm{Si}_{6} \mathrm{O}_{18}$ and $\mathrm{Na}_{2} \mathrm{Ca}_{4}\left(\mathrm{PO}_{4}\right)_{2} \mathrm{SiO}_{4}$ phases and the appearance of two halos at $2 \Theta$ values of $26^{\circ}$ and $32^{\circ}$, which correspond respectively to (002) and (211) hydroxyapatite reflection planes. Finally, after nine months, XRD pattern is similar to that of the control bone and exhibits the biocompatibility and the chemical reactivity of our composite. FTIR analyses of the reacted material after implementation show some alterations of the biomaterial. This is due to several reactions between bone and 46S6-10Zn. Thus, after one month, the presence of amide I at a wave- number of $167 \mathrm{~cm}^{-1}$ indicates the mineralization of bone tissue [18-19]. After four and nine months, the crystallization and the changing of 46S6-10Zn is seemed by the appearance of all peaks characterizing biological apatite. This data highlights the bioactivity of our composite. It has been demonstrated that dissolution products from bioactive glasses up -regulate the expression of genes that control osteogenesis [20,21], which explains the high rate of bone formation in comparison to other inorganic ceramics such as hydroxyapatite [22].

The degradation of the composite (46S6-10Zn) with time of implantation is seemed by its progressive degradation in favor of the formation and crystallization of new bone. Moreover, the crystallization of the new formed apatite layer is poor. Therefore, we notice the appearance of bands characterizing a stretching vibration of $\mathrm{C}=\mathrm{O}$ of the 
amide I $[18,19]$, with the persistence of the maximum characterizing the porous glass ceramic. Four months later, it was nearly completely degraded and replaced by bone tissues reported by the appearance of all bands charactering bone. Therefore, the band at $1542 \mathrm{~cm}^{-1}$ (amide II) arising from the combination of C-N stretching and N-H bending vibrations of the protein bone can be related to the protein matrix formation of implanted bone $[18,19]$. The crystallization of this HA layer is more shown by the appearance of amide II $[18,24]$ and carbonate bands $[18,19]$. All results highlight the deposition of the apatite layer upon to the silicon layer when brought in contact with body fluids $[25,27]$. Nine months later, all these bands increase in intensity and take the same form of biological apatite of bone. The contact between the biomaterial surface and the SBF solution leads to the formation of a hydrated silica layer on this surface and induces the deposition of HA. Silanol groups could be specific sites of apatite nucleation [7].

The bioactivity of 46S6-10Zn after its implementation depends on its chemical composition [27]. The amounting of $\mathrm{Ca} / \mathrm{P}$ ratio over time is an indication of progressive mineralization with time progressing. This finding highlights the good role of $\mathrm{Zn}$ in the mineralization of the interface: bone- 46S6-10Zn. The incorporation of mineral ions such as zinc or silicate in calcium phosphate ceramics showed an increase of osteoblasts attachment and proliferation [28]. After one month of implementation, the slowly decreasing of $\mathrm{Si}$ in the interface of $46 \mathrm{~S} 6-10 \mathrm{Zn}$ is explained by the slowly dissolution of biomaterial which leads to its release. The increasing of Si may be due to the breaking of the Si-O-Si bond and favorites the formation of $\mathrm{Si}-\mathrm{OH}$ and $\mathrm{Si}(\mathrm{OH})_{4}$ groups at the glass/bone interface and which induces heterogeneous nucleation of the apatite with the progression time. Orthosilicate acid, $\mathrm{Si}(\mathrm{OH})_{4}$, has been shown to stimulate osteoblastic 
differentiation and the formation of type I collagen in human osteoblasts [29]. Whereas, after four and nine months, the silicon value decreased and tended to 0 after nine months, this highlights the degradation of the porous glass ceramic and its replacement by bone cells. Data reported by the MAS-NMR confirm the previous findings reported by the other analyses.

Therefore, ${ }^{29} \mathrm{Si}$ MAS-NMR spectra of the implanted 46S6-10Zn illustrate the decreasing of $\mathrm{Q}^{2}$ and $\mathrm{Q}^{3}$ species, with time progression, in favor of the increasing of $\mathrm{Q}^{4}$. This result demonstrates the degradation of the biomaterial and the formation of a siliconrich layer on the surface of the biomaterial. Surface hydroxyl groups play an important role in bioactivity [3]. Silica gel in the bioactive glass surface provides a large number of silanol ( $\mathrm{Si}-\mathrm{OH})$ terminations, which flex to match the crystals of hydroxyapatite and act as nucleation sites [30]. After six months, these species are disappearing. This exhibits the degradation of our composite and its replacement by bone. Glass bioactivity leads to both osteoconduction and osteoproduction [31] as a consequence of rapid reactions on the bioactive glass surface.

The 31P MAS-NMR spectrum obtained for the glass ceramic and the results of its deconvolution before implementation, demonstrate the location of 2 distinct contributions at $3 \mathrm{ppm}$ and $8 \mathrm{ppm}$. There are characteristics of phosphorus species of an orthophosphates environment $\mathrm{Q}^{0}[32]$. The attenuation of species $\mathrm{Q}_{\mathrm{a}}{ }^{0}$ and $\mathrm{Q}_{\mathrm{c}}{ }^{0}$ with time progression and the increasing of $\mathrm{Q}_{\mathrm{HA}}{ }^{0}$ highlight the degradation of bioimplant and its replacement by the bone. These findings exhibit also the bioactivity of our composite in the first time and in the second time the good effect of $\mathrm{Zn}$ incorporation in the vitreous matrix which stimulates osteobalst formation and inhibits osteoclast differentiation. To better understand the evolutionary phenomena of the degradation of the hybrid (46S6- 
10Zn) and its replacement by a new calcified bone, we have deepened our physicochemical study by histological exploration. Therefore, the degradation of this composite increased with time progression in favor of bone mineralization. These findings are correlated to the bioacompatibility, the degradability and the presence of pores which ensure the integration of bone cells in biomaterial. This osseointegration phenomena increase with time progression and lead to almost total degradation of 46S6-10Zn. The increasing microporosity may provide an increased surface area for the action of angiogenic and other proteins leading to the formation of blood vessels and promoting bone induction by osteoblasts at early time points $[33,34]$. In the other hand, it is may be due to the presence of $\mathrm{Zn}$ in the vitreous matrix of $46 \mathrm{~S} 6-10 \mathrm{Zn}$ and which encouraged the differentiation and the development of mineralized bone tissue. Zinc is an essential trace metal known to have stimulatory effects on bone formation in vitro and in vivo studies [35].

\section{Conclusion}

This study aimed to evaluate the behavior of our porous glass ceramic doped with $\mathrm{Zn}$ and $\mathrm{Ti}(46 \mathrm{~S} 6-10 \mathrm{Zn})$ before and after its implementation in bone defect. This evaluation realized by several physico-chemical explorations through XRD, FTIR, EDS and ${ }^{29} \mathrm{Si}$,

${ }^{31} \mathrm{P}$ MASS-NMR. Therefore, XDR and FTIR illustrate the degradation and the neoformation of bone by the disappearance of peaks characterizing amorphous and crystalline phases of $46 \mathrm{~S} 6-10 \mathrm{Zn}$, and their replacement by peaks similar to those of biological apatite. Moreover, EDS shows the mineralization of bone tissue by the 
increasing of $\mathrm{Ca} / \mathrm{P}$ ratio with time progression from 1.33 after one month to 1.88 nine months later. Also, it highlights progressive degradation of 46S6-10Zn, as indicated by the reduction of $\mathrm{Zn}$ and $\mathrm{Si}$ concentrations with time progression. MAS-NMR illustrates the degradation of biomaterial, then ${ }^{29} \mathrm{Si}$ MAS-NMR indicates the disappearance of $\mathrm{Q}^{2}, \mathrm{Q}^{3}$ and $\mathrm{Q}^{4}$ species after six months of implementation. Whereas ${ }^{31} \mathrm{P}$ MAS-NMR shows the disappearances of $\mathrm{Q}^{0}{ }_{\mathrm{C}}$ and $\mathrm{Q}^{0}$ a species in favor of the development of $\mathrm{Q}^{0}{ }_{\mathrm{HA}}$. Finally, histological exploration illustrates the osseointegration and the biodegradation of the composite by the progression of the osteoblasts' deposition in the pores of biomaterial leading after nine months to it's totally degradation and its replacement by mineralized and osteoid bone. All these data highlight the good effect of incorporation of $\mathrm{Zn}$ and $\mathrm{Ti}$ in the matrix of bioglass.

Acknowledgements:

The authors would like to acknowledge Francis GOUTTEFANGEAS and Loic JOANNY(CMEBA, University' of Rennes 1), for their help and their contribution during this work, and radiotherapy service in Sfax for their help for the sterilization of materials. Also, they would like to thank Professor A. Barroug from University of Cadi Ayyad, Marrakech, Morroco. This work concerns a part of our FINCOME program and collaboration supported by CNRST, Rabat, Morroco. 
References:

[1] A.F. Fetner, M.S. Manigan, S.H. Low, Penodonlal repair using Perioglas in nonhuman primates: Clinical and histologie observations, Compendium. 15 (1994) 932939.

[2] L. L .Hench, H.A. Paschall, Direct chemical bond of bioactive glass-ceramic materials to bone and muscle, J. biomed. Mater. Res A. 7 (1973) 25-42.

[3] L.L. Hench, Bioceramics, J .Am .Ceram. Soc. 81(1998) 1705-1728.

[4] I.D. Xynos, A.J. Edgar, L.D.K. Buttery, L.L. Hench, J.M. Polak, Gene expression profiling of human osteoblasts following treatment with the ionic products of Bioglass ${ }^{\circledR}$ 45S5 dissolution, J .Biomed. Mater. Res. 55 (2001) 151-7.

[5] H.Oudadesse, E. Dietrich, X.V. Bui, Y. Le Gal, P. Pellen, G. Cathelineau , Enhancement of cells proliferation and control of bioactivity of strontium doped glass, Appl. Surf. Sci. 257 (2011) 8587-8593.

[6] E. Dietrich , H. Oudadesse , A. Lucas-Girot, M. Mami, In vitro bioactivity of meltderived glass 46S6 doped with magnesium, Biomed. Mater. Res A.10 (2009) 100231901.

[7] M. Erol, A. Özyuguran, Ö. Çelebican, Synthesis, Characterization, and In Vitro Bioactivity of Sol-Gel-Derived Zn, Mg, and Zn-Mg Co-Doped Bioactive Glasses, Chem. Eng. Technol.33 (2010) 1066-1074.

[8] X.V. Bui, H. Oudadesse, Y. Le Gal, A. Mostafa, P.Pellen , G. Cathelineau, Chemical reactivity of biocomposite glass-zoledronate, J. Aust. Ceram. Soc. 46 (2010) 24-28.

[9] H.G.Classen, U.Gröber, D.Löw, H. Schimidt, H.Strake, Zinc Deficiency: Symptoms, causes, diagnosis and therapy, Med. Monatsschr. Pharm. 34 (2011)87-95. 
[10] T.J. McCarthy, J.J .Zeelie, D.J. Krause, The antimicrobial action of zinc ion/ antioxidant combination, Clin. Pharmacol. Ther. 17 (1992) 51-4.

[11] N.W. Solomons, Mild human zinc deficiency produces an imbalance between cellmediated and humoral immunity, Nutr. Rev. 56 (1998) 27-28.

[12] H.S. Hsieh, J.M. Navia, Zinc deficiency and bone formation in guinea pig alveolar implants, J .Nutr. 110 (1980) 1581-8.

[13] G. Oner, B. Bhaumick and R .M. Bala, Effect of zinc deficiency on serum somatomedin levels and skeletal growth in young rats, Endocrinol. 114 (1984) 1860-3. [14] M.Yamaguchi, R.Yamaguchi, Action of zinc on bone metabolism in rats. Increases in alkaline phosphatase activity and DNA content, Biochem. Pharmacol. 35 (1986) $773-7$.

[15] S.L. Hall, H.P. Dimai, J.R. Farley, Effects of zinc on human skeletal alkaline phosphatase activity in vitro, Calcif .Tissue. Int. 64 (1999) 163-72.

[16] Li. P. Ohtsuki, C. Kokubo, T. Nakanishi, K. Soga, N. de Groot K, the role of hydrated silica, titania and aluminia in inducing apatite on implant, J .Biomed. Mater. Res. 28 (1994)7-15

[17] E. Wers., H. Oudadesse, Élaboration d'un biomatériau poreux à base d'une matrice vitreuse induisant le phénomène d'ostéoinduction, Rennes, France, 2014.

[18] K. Singh, K.S. Lee, D. Lee, Y. K. Kim, K. Ch. Kim, Spectroscopic technique as a diagnostic tool for early detection of osteoporosis, J. Mech. Sci. Technol. 24 (2010) $1661-1668$.

[19] L. L. Hench, J. M. Polak, I. D. Xynos, L. D. K. Buttery, Bioactive materials to control cell cycle, Mater. Res. Innovat. 3 (2000) 313-323. 
[20] I.D. Xynos , M.V. Hukkanen , J.J. Batten , L.D. Buttery , L.L. Hench , J.M. Polak , Bioglass 45S5 stimulates osteoblast turnover and enhance bone formation in vitro: implication and application for bone tissue engineering, Calc. Tiss. Int. 67 (2000) 321329.

[21] S. Garip, F. Severcan, determination of simvastatin- induced changes in bone composition and structure by Fourier transform infrared spectroscopy in rat animal model, J. Pharm. Biomed. Anal. 52 (2010) 580-588.

[22] N. Kourkoumelis , M .Tzaphlidou, Spectroscopic assessment of normal cortical bone: differences in relation to bone site and sex, Scientific. World. J. 10 (210) 402-412 [23] Ö.H. Andersson, K.H. Karlsson, Calcium phosphate formation at the surface of bioactive glass in vivo, J. Non-Crystal. Solids. 12 (1990) 290-296.

[24] L.L. Hench, J.K. West, Biological applications of bioactive glasses, Life. Chem . Rep. 13 (1996) 187-241.

[25] M. Ogino, F. Ohuchi, L.L. Hench. Compositional dependence of the formation of calcium phosphate films in bioglass, J .Biomed. Mater. Res.14 (1980) 55-64.

[26] K. Ishikawa, Y. Miyamoto, T. Yuasa, A. Ito, M. Nagayama, K.

Suzuki, Fabrication of $\mathrm{Zn}$ containing apatite cement and its initial evaluation using human osteoblastic cells, Biomaterials. 23 (2002) 423-8.

[27] D.M. Reffitt, N. Ogston, R .Jugdaohsingh, H.F.J. Cheung, B.A.J. Evans, R.P.H. Thompson, J.J .Powell, G.N. Hampson, Orthosilicic acid stimulates collagen type 1 synthesis and osteoblastic differentiation in human osteoblast-like cells in vitro, Bone . $32(2003) 127-135$.

[28] G.K. Toworfe, S. Bhattacharyya, R. J. Composto, C.S. Adams, I.M. Shapiro, P. Ducheyne, Effect of functional end groups of silane self-assembled monolayer surface 
on apatite formation, fibronectin adsorption and osteoblast cell function, J .Tissue. Eng. Regen. Med. 3 (2009)26-36.

[29] P. Li , C. Ohtsuki , T. Kokubo , K. Nakanishi , N. Soga , K . de Groot, The role of hydrated silica, titania, and alumina in inducing apatite on implants, J. Biomed. Mater. Res. 28 (1994) 7-15.

[30] H. Grussaute, L. Montagne, G. Palavit, J.L. Bernard, Phosphate speciation in $\mathrm{Na}_{2} \mathrm{O}-\mathrm{CaO}-\mathrm{P}_{2} \mathrm{O}_{5}-\mathrm{SiO}_{2}$ and $\mathrm{Na}_{2} \mathrm{O}-\mathrm{TiO}_{2}-\mathrm{P}_{2} \mathrm{O}_{5}-\mathrm{SiO}_{2}$ galsses, J .Non- Cryst. Solids. 2 (2000) $312-317$

[31] A. Bignon, J. Chouteau, J. Chevalier, J.G. Fantozzi, J.P. Carrer, P. Chavassieux, G. Bovin, M. Melin, D. Hartmann, Effect of micro and macroporosity of bone substitutes on their mechanical properties and cellular response, J. Mater. Sci. Mater. Med. 14 (2003) 1089-1097.

[32]S. Ohtsubo, M. Matsuda, M. Takekawa, Angiogenesis after sintered bone implementation in rat parietal bone, Histol .Histopathol.18 (2003)153-63.

[33] B .Otsuki, M. Takemoto, S. Fujibayashi, M. Neo, T. Kokubo, T. Nakamura, Pore throat size and connectivity determine bone and tissue ingrowth into porous implants: three-dimensional micro-CT based structural analyses of porous bioactive titanium implants, Biomaterials. 27 (2006) 5892-900.

[34] M.Yamaguchi, K.Inamoto, Y. Suketa, Effect of essential trace metals on bone metabolism in weanling rats: Comparison with zinc and other metals action, Res. Exp. Med. 186 (1986) 337-342.

[35] M. Yamaguchi, H. Oishi, Y. Suketa, Stimulatory effects of zinc on bone formation in tissue culture, Biochem. Pharmacol. 36 (1987) 4007-4012. 
Figures captions:

Figure 1: Steps of surgical operation

Figure 2: XRD pattern of porous glass ceramic doped with Zinc (46S6-10Zn) before and after one, four and nine months of implementation in critical diaphyseal bone defect in rabbit.

Figure 3: FTIR spectra of porous glass ceramic doped with zinc (46S6-10Zn) before and after one, four and nine months of implementation in critical diaphyseal bone defect in rabbit.

Figure 4: $\mathrm{Ca} / \mathrm{P}$ ratio (EDS) obtained from the chemical analysis of the porous glass ceramic doped with Zinc (46S6-10Zn) before and after one, four and nine months of implementation in critical diaphyseal bone defect in rabbit.

Figure 5: Si and $\mathrm{Zn}$ value (EDS) obtained from the chemical analysis of the porous glass ceramic doped with Zinc (46S6-10Zn) before and after one, four and nine months of implementation in critical diaphyseal bone defect in rabbit.

Figure $6:{ }^{29} \mathrm{Si}$ MAS-NMR spectra of porous glass ceramic doped with zinc (46S6-10Zn) before and after one, four and six months of implementation in critical diaphyseal bone defect in rabbit.

Figure 7: ${ }^{31} \mathrm{P}$ MAS-NMR spectra of porous glass ceramic doped with zinc (46S6-10Zn) before and one, four and six months after implementation in critical diaphyseal bone defect in rabbit. 
Figure 8: Goldner's trichrome staining $(10 \times$ objective $)$. Histological sections of the interface between porous glass ceramic (46S6-10Zn) and bone after one month after implementation in critical diaphyseal bone defect in rabbit:

* indicates porous glass ceramic doped with zinc (46S6-10Zn)

\# indicates mineralized bone

Figure 9: Goldner's trichrome staining $(10 \times$ objective $)$. Histological sections of the interface between porous glass ceramic (46S6-10Zn) and bone four months after implementation in critical diaphyseal bone defect in rabbit:

* indicates porous glass ceramic doped with zinc (46S6-10Zn)

\#indicate mineralized bone and

(a) indicate the osteoid bone.

Arrows: indicates the osseointegration process

Figure 10: Goldner's trichrome staining $(10 \times$ objective $)$. Histological sections of the interface between porous glass ceramic (46S6-10Zn) and bone after nine months of implementation in critical diaphyseal bone defect in rabbit:

\#indicate mineralized bone and

Arrows indicate the osteointegration process.

Figure 11: Goldner's trichrome staining $(10 \times$ objective $)$. Histological sections of the interface between porous glass ceramic (46S6-10Zn) and bone after nine months of implementation in critical diaphyseal bone defect in rabbit:

\# indicates mineralized bone and

(a) indicate the osteoid bone. 


\section{ACCEPTED MANUSCRIPT}
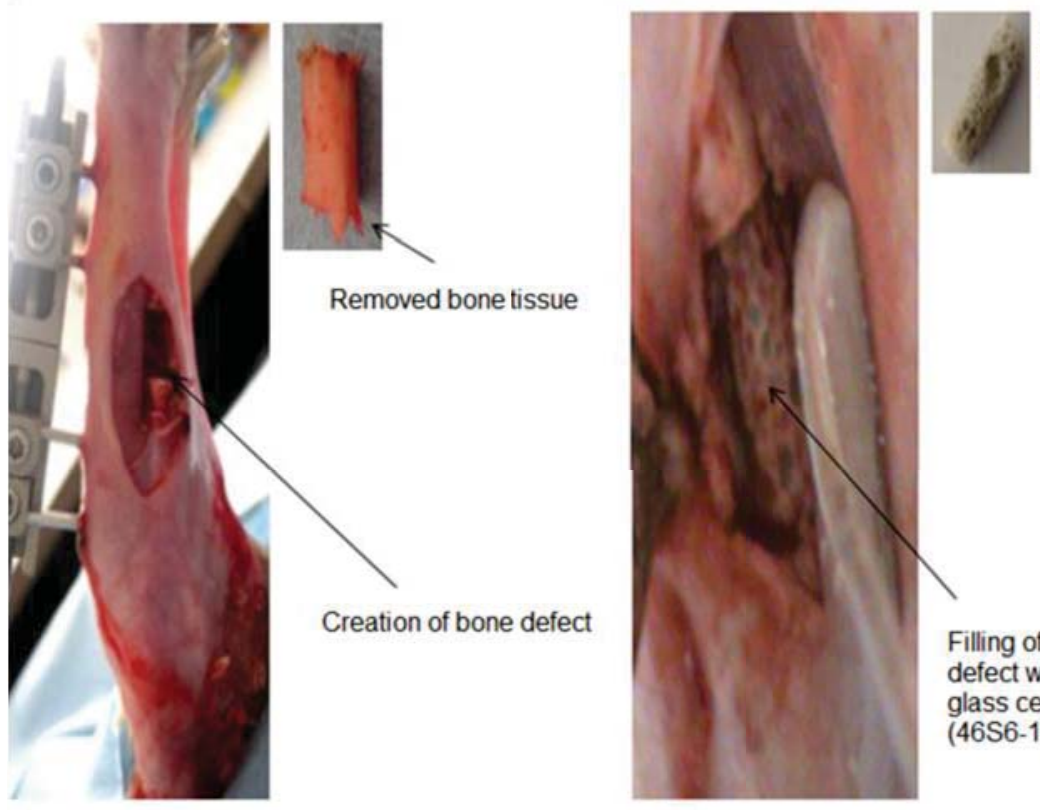

Porous glass ceramic

(46S6-10Zn)

Filling of bone

defect with porous

glass ceramic

(46S6-10Zn)

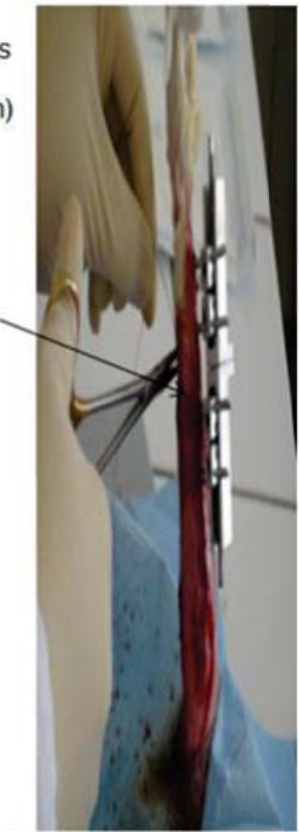

ф: $\mathrm{Na}_{2} \mathrm{Ca}_{4}\left(\mathrm{PO}_{4}\right)_{2} \mathrm{SiO}_{4}$

a: $\mathrm{Na}_{4} \mathrm{Ca}_{4} \mathrm{Si}_{6} \mathrm{O}_{18}$

: Hydroxyapatite

(211)
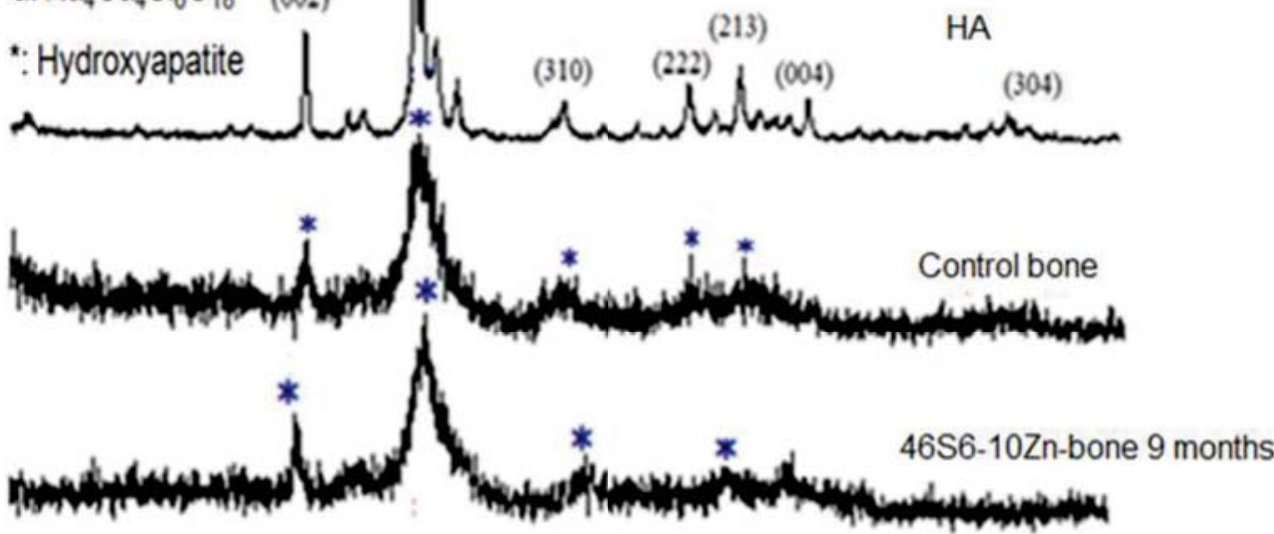

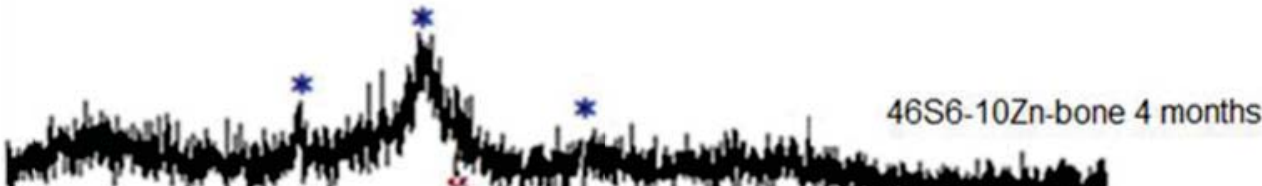

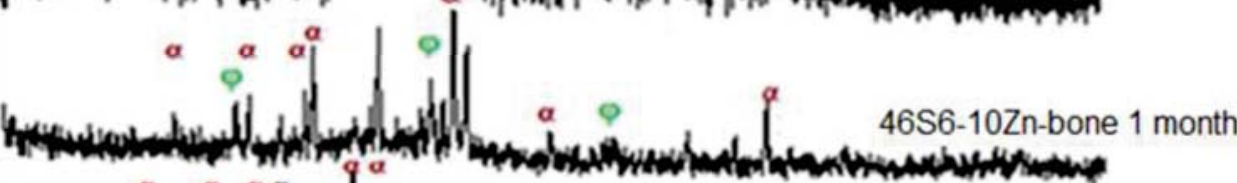

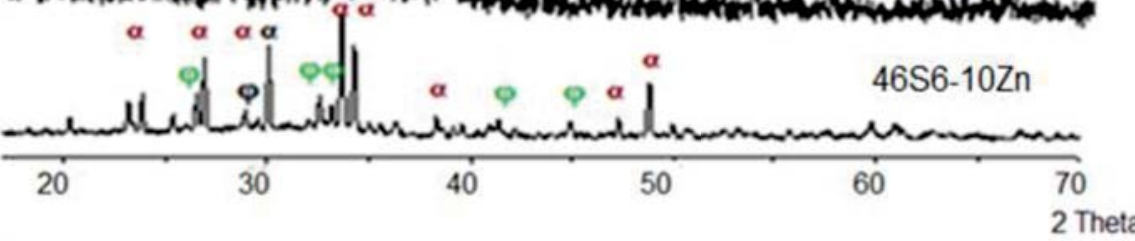




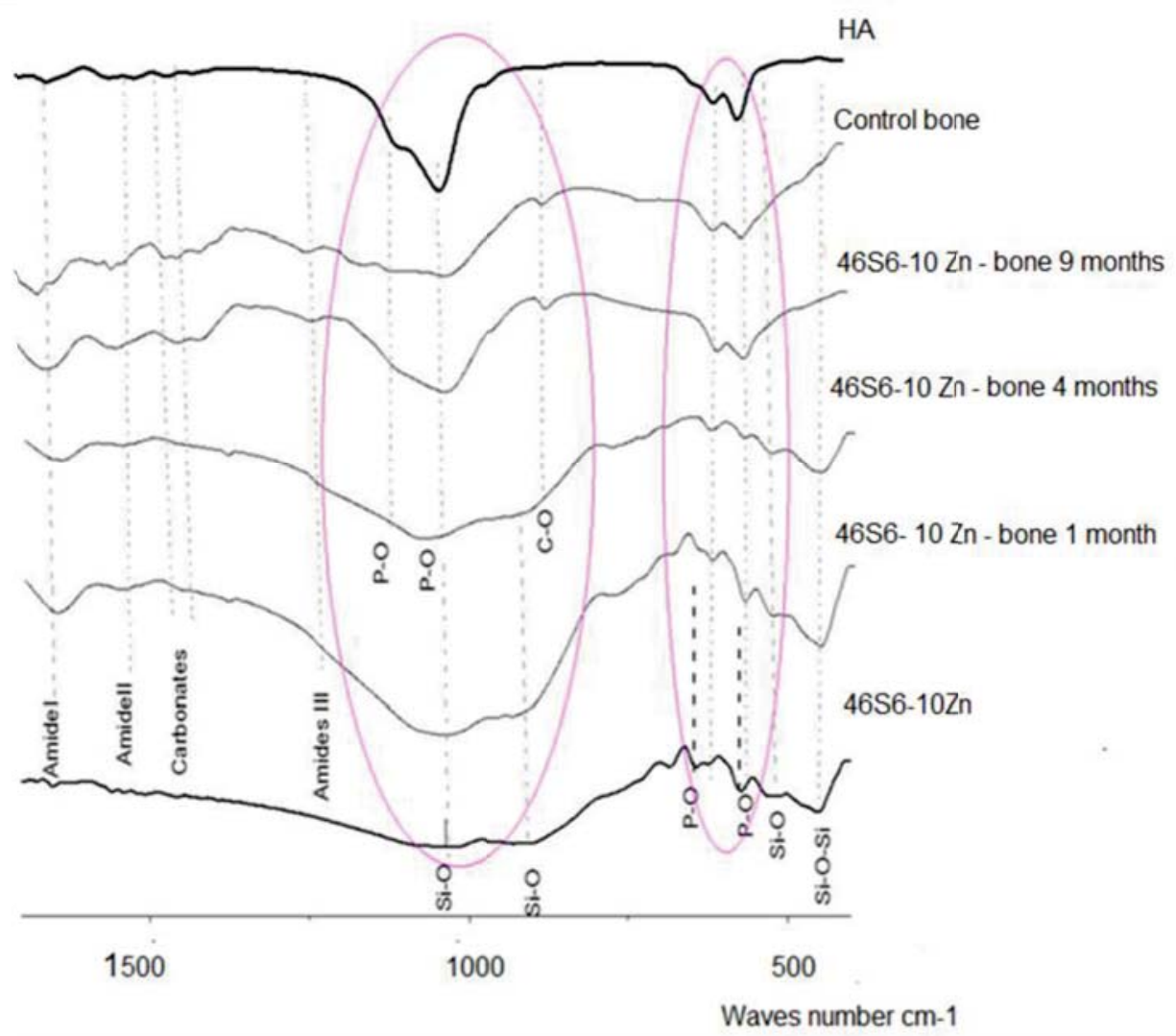



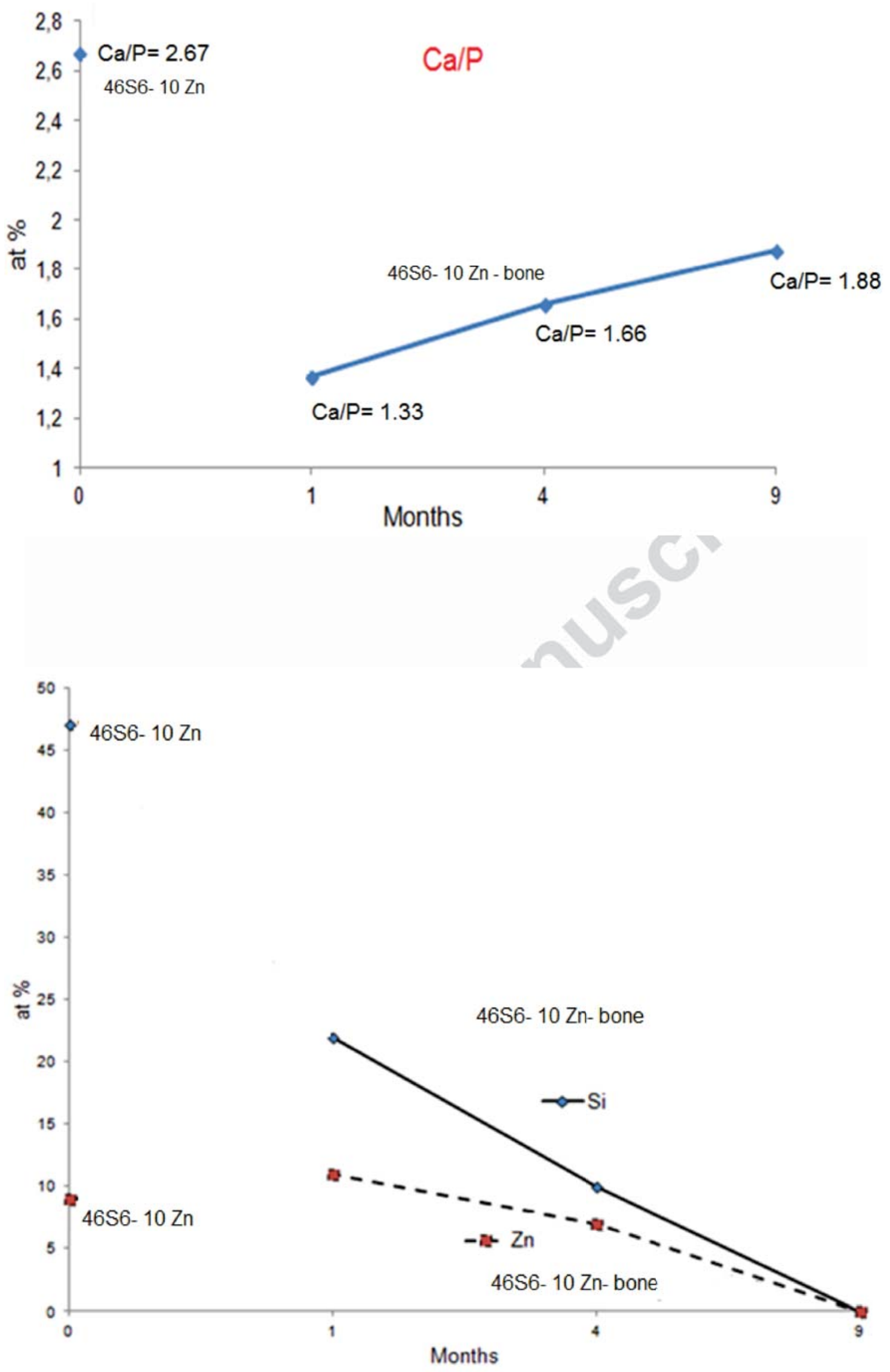


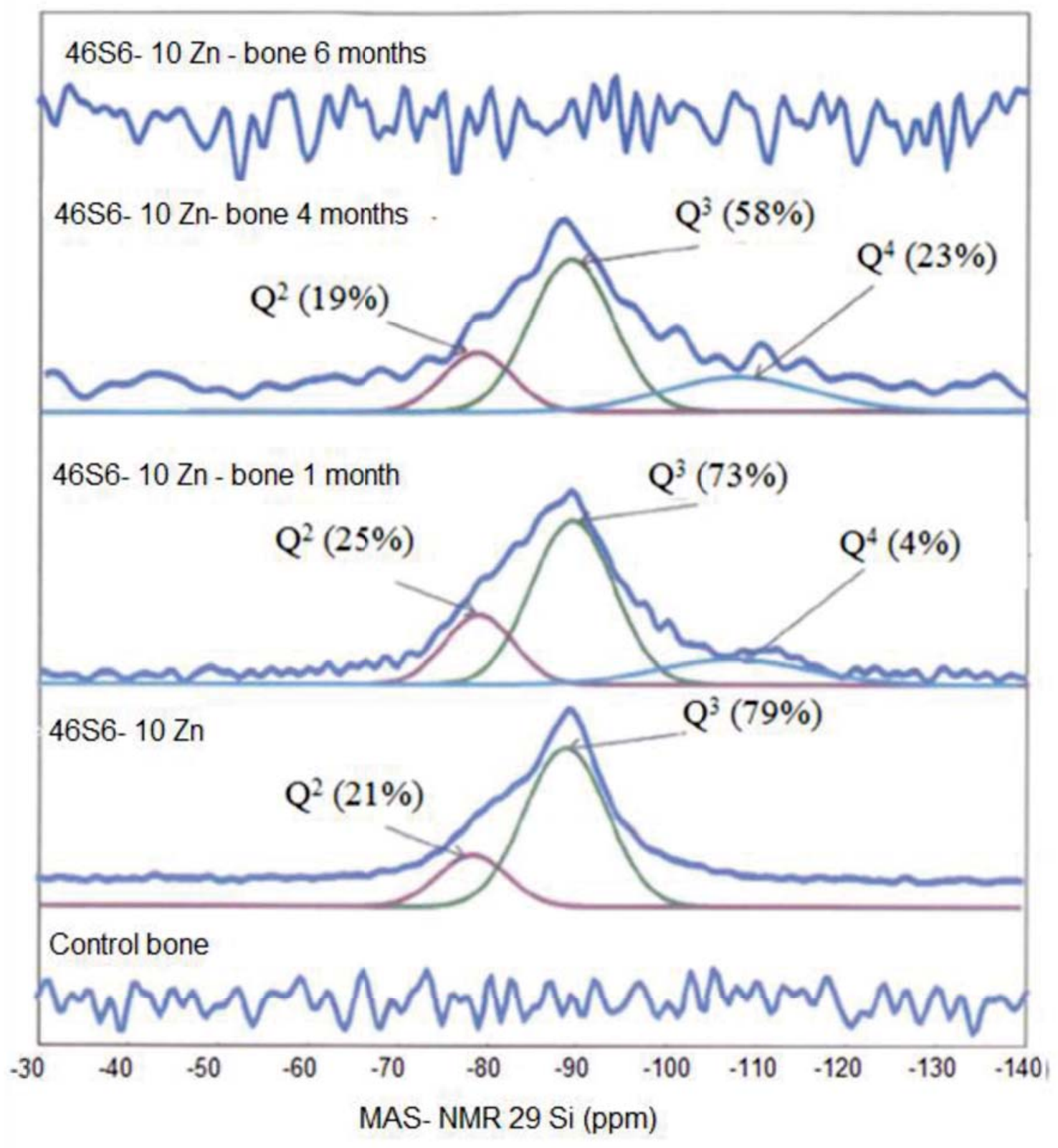




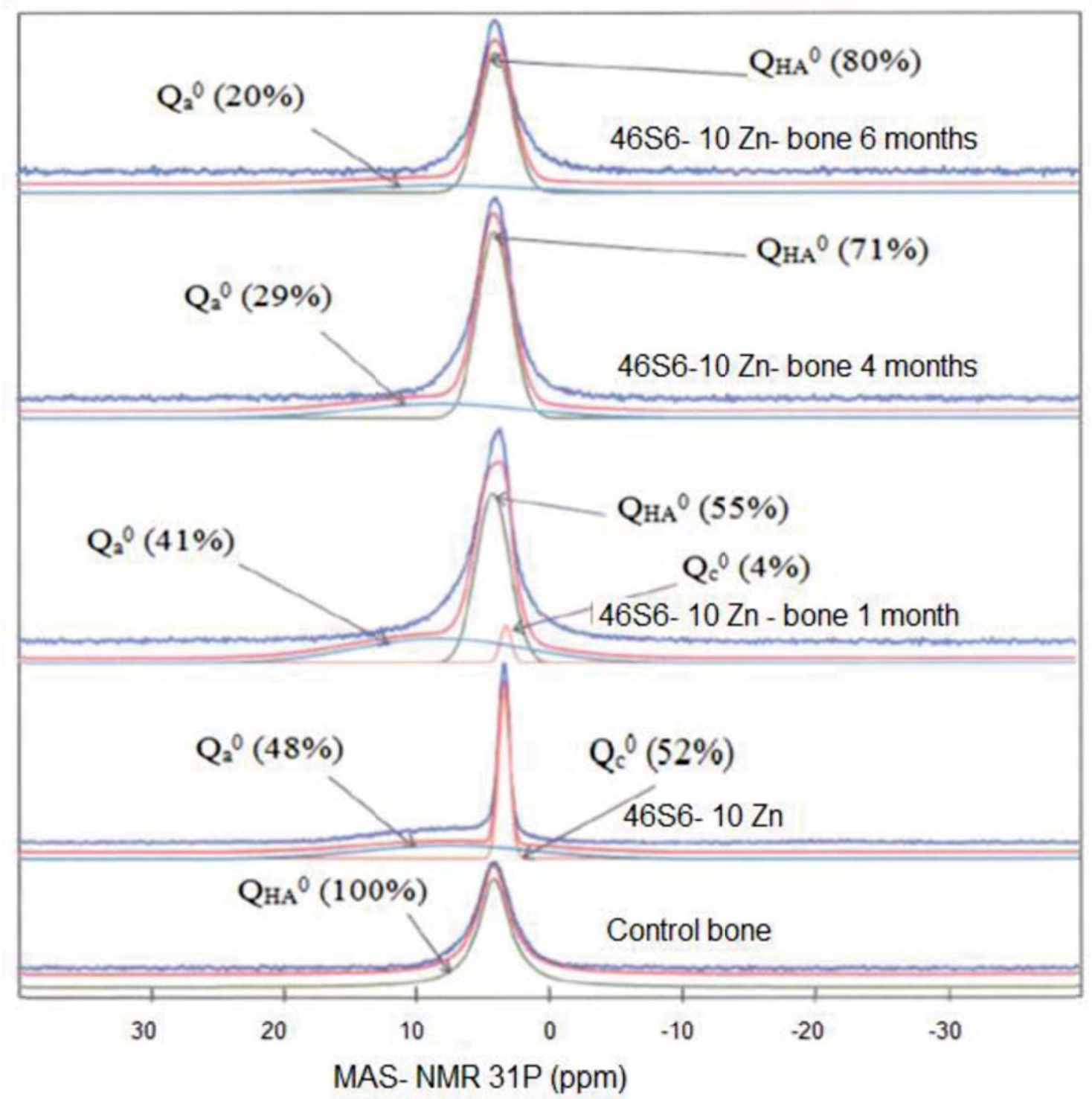




\section{ACCEPTED MANUSCRIPT}
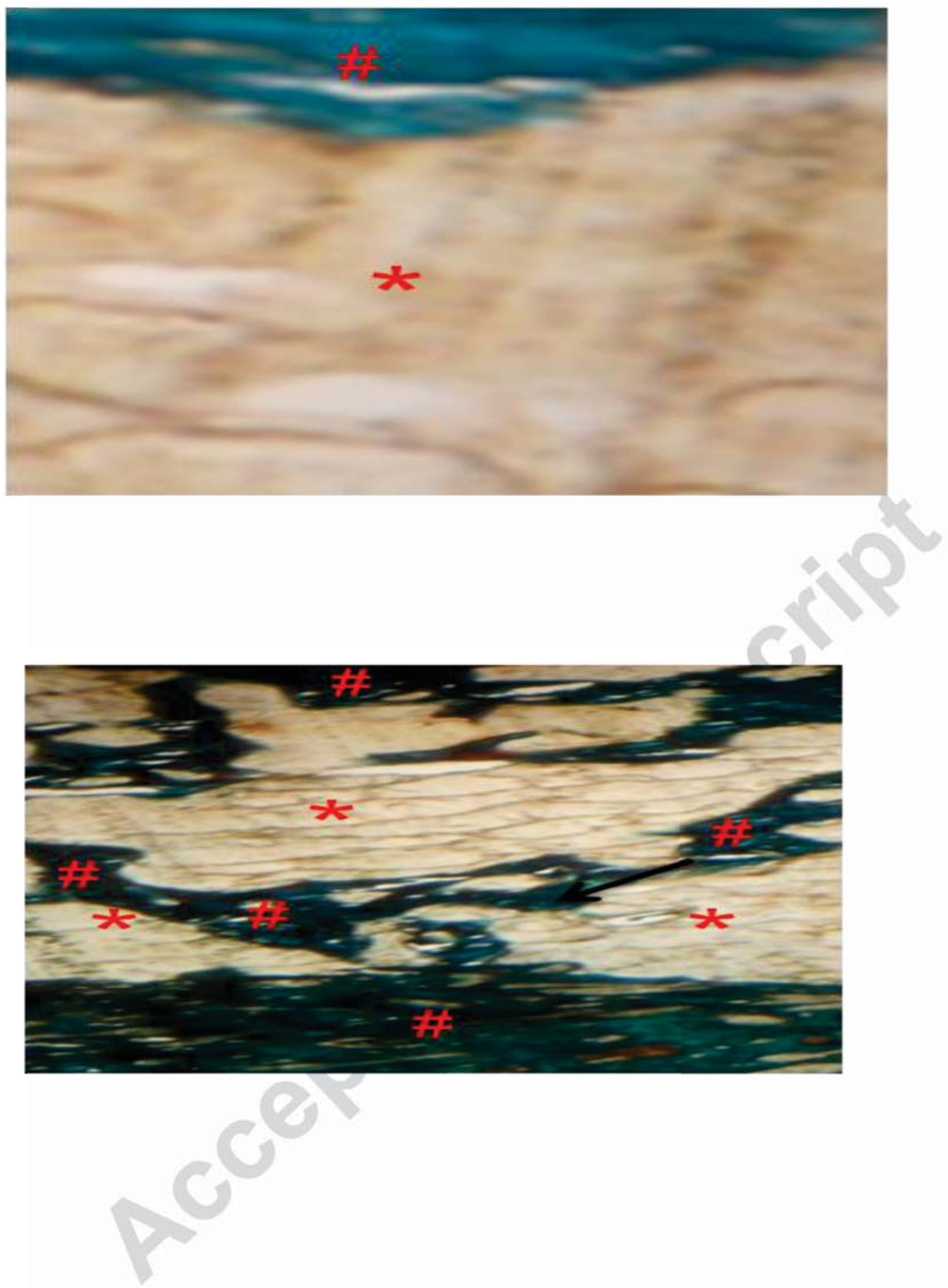


\section{ACCEPTED MANUSCRIPT}
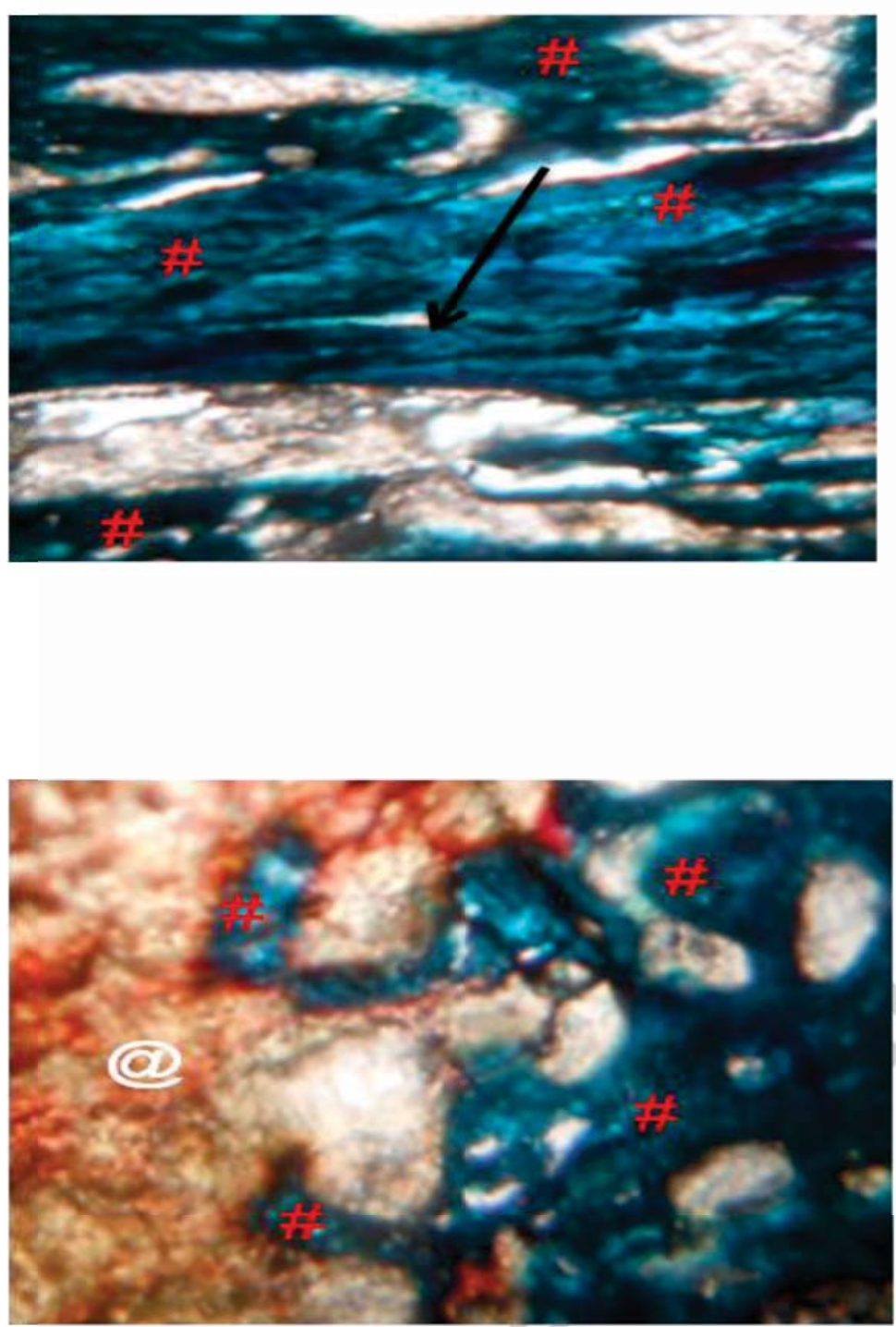

Tables captions :

Table 1: Contribution and chemical shifts of different species in ${ }^{29} \mathrm{Si}$ spectra of bioactive pure glass (46S6) and porous glass ceramic doped with zinc (46S6-10Zn) before implementation.

Table 2: Contribution and chemical shifts of different species in ${ }^{29} \mathrm{Si}$ spectra of porous glass ceramic doped with zinc (46S6-10Zn) after one, four and six months after implementation. 
Table 3: Contribution and chemical shifts of different species in ${ }^{31} \mathrm{P}$ spectra of bioglass pure (46S6) and porous glass ceramic doped with zinc (46S6-10Zn) before implantation.

Table 4: Contribution and chemical shifts of different species in ${ }^{31} \mathrm{P}$ spectra of porous glass ceramic doped with zinc (46S6-10Zn) after one, four and six months of implementation

\begin{tabular}{|c|c|c|c|c|}
\hline \multirow{2}{*}{} & \multicolumn{2}{|c|}{$\mathrm{Q}^{2}$} & \multicolumn{2}{c|}{$\mathrm{Q}^{3}$} \\
\cline { 2 - 5 } & $\delta(\mathrm{ppm})$ & $\%$ & $\delta(\mathrm{ppm})$ & $\%$ \\
\hline Pure bioactive glass (46S6) & -79 & 80 & -87 & 20 \\
\hline $\begin{array}{c}\text { Porous glass ceramic doped } \\
\text { with zinc (46S6-10Zn) }\end{array}$ & -79 & 21 & -89 & 79 \\
\hline
\end{tabular}

\begin{tabular}{|c|c|c|c|c|c|c|}
\hline \multirow{2}{*}{} & \multicolumn{2}{|c|}{$\mathrm{Q}^{2}$} & \multicolumn{2}{c|}{$\mathrm{Q}^{3}$} & \multicolumn{2}{c|}{$\mathrm{Q}^{4}$} \\
\cline { 2 - 7 } & $\delta(\mathrm{ppm})$ & $\%$ & $\delta(\mathrm{ppm})$ & $\%$ & $\delta(\mathrm{ppm})$ & $\%$ \\
\hline 1 Month & -79 & 25 & -89 & 73 & -108 & 4 \\
\hline 4 Months & -79 & 19 & -89 & 58 & -108 & 23 \\
\hline 6Months & 0 & 0 & 0 & 0 & 0 & 0 \\
\hline Control bone & 0 & 0 & 0 & 0 & 0 & 0 \\
\hline
\end{tabular}




\begin{tabular}{|l|c|c|c|c|}
\hline \multirow{2}{*}{} & \multicolumn{2}{|c|}{$\mathrm{Q}^{0}{ }_{\mathrm{c}}$} & \multicolumn{2}{c|}{$\mathrm{Q}_{\mathrm{a}}^{0}$} \\
\cline { 2 - 5 } & $\delta(\mathrm{ppm})$ & $\%$ & $\delta(\mathrm{ppm})$ & $\%$ \\
\hline Pure bioactive glass & 7.5 & 100 & 0 & $\mathrm{O}$ \\
$(46 \mathrm{~S} 6)$ & 3 & 52 & 8 & 48 \\
\hline $\begin{array}{l}\text { Porous glass ceramic } \\
\text { doped with Zinc (46S6- } \\
\text { 10Zn) }\end{array}$ & & & & \\
\hline
\end{tabular}

\begin{tabular}{|c|c|c|c|c|c|c|}
\hline & \multicolumn{2}{|c|}{$\mathrm{Q}^{0}{ }_{\mathrm{c}}$} & \multicolumn{2}{c|}{$\mathrm{Q}^{0}{ }_{\mathrm{HA}}$} & \multicolumn{2}{c|}{$\mathrm{Q}^{0}{ }_{\mathrm{a}}$} \\
\cline { 2 - 7 } & $\delta(\mathrm{ppm})$ & $\%$ & $\delta(\mathrm{ppm})$ & $\%$ & $\delta(\mathrm{ppm})$ & $\%$ \\
\hline 1 Month & 3 & 4 & 4 & 55 & 8 & 41 \\
\hline 4 Months & 3 & 0 & 4 & 71 & 8 & 29 \\
\hline 6 Months & 3 & 0 & 4 & 80 & 8 & 20 \\
\hline Control bone & 0 & 0 & 4 & 100 & 0 & 0 \\
\hline
\end{tabular}

